\title{
Spectrin Isoforms in the Mammalian Retina
}

\author{
Tomoki Isayama,' Steven R. Goodman, ${ }^{2}$ and lan S. Zagon' \\ 'Department of Neuroscience and Anatomy, The Pennsylvania State University, The M. S. Hershey Medical Center, \\ Hershey, Pennsylvania 17033 and ${ }^{2}$ Department of Structural and Cellular Biology, University of South Alabama \\ College of Medicine, Mobile, Alabama 36688
}

Spectrin is a major component of the mammalian neuronal cytoskeleton. In the CNS, three isoforms of brain spectrin are known to exist: a cellular and dendritic isoform, (240/ 235E), related to neurons and glia; a cellular and axonal isoform, (240/235), related to neurons; and an isoform specific for astrocytes, $(240 / 235 A)$. In the present study, brain spectrins (240/235E) and (240/235) were localized within the mouse retina and optic nerve. Immunoblot analyses of proteins isolated from mouse retinas utilizing polyclonal antibodies to either brain spectrin (240/235) or brain spectrin $(240 / 235 E)$ revealed that these spectrins are present in the retina and that the two isoforms are the same molecular weights as those found in the brain. Immunocytochemical studies revealed that spectrin (240/235E) was localized in cell bodies of the inner nuclear, outer nuclear, and ganglion cell layers, and processes arborizing within the inner and outer plexiform layers. Spectrin (240/235) was distributed diffusely within the retina, lightly staining neurons in both the inner nuclear and outer nuclear layers, and the ganglion cell layer. In contrast to the situation found in the brain, spectrin (240/235) was but one of the axonal forms in the retina. We found that spectrin $(240 / 235 E)$ was also present in the axon-rich fiber layer and in the optic nerve and was often associated with fibrous elements. Spectrin (240/235) was also detected in the nerve fiber layer and optic nerve, but this isoform was not localized to fibers. These results indicate that the cytoskeletal proteins spectrin (240/235) and $(240 / 235 E)$ are present in the retina and optic nerve, but the distribution of the two subtypes may differ somewhat from the pattern found in the brain. A spectrin-based membrane cytoskeleton in the retina may be related to actin-membrane attachment, strengthening of the membrane fabric, cellular architecture, axonal transport, and neural transmission.

Spcctrin is a major component of the cytoplasmic surface of the red blood cell ( $\mathrm{rbc}$ ) plasma membrane and is involved in maintaining rbc shape, membrane stability, and the regulation of lateral mobility of integral membrane proteins (Goodman et al., 1988; Bennett, 1990). Spectrin-related molecules are also present in many nonerythroid tissues and cells (Goodman et al., 1981; Bennett et al., 1982; Burridge et al., 1982; Glenney et al.,

Received Mar. 14, 1991; revised June 7, 1991; accepted June 13, 1991.

This work was supported by NIH Grants NS-21246 and NS-19357. We thank Gretchen Allison for technical support with the immunoblot preparations and Drs. W. D. Eldred and P. Sterling for critical reading of the manuscript.

Correspondence should be addressed to Dr. Ian S. Zagon, Department of Neuroscience and Anatomy, The M. S. Hershey Medical Center, Hershey, PA 17033. Copyright $(\mathcal{C} 1991$ Society for Neuroscience $0270-6474 / 91 / 113531-08 \$ 05.00 / 0$
1982; Repasky et al., 1982). Brain spectrin, also known as fodrin (Levine and Willard, 1981), calspectin (Kakiuchi et al., 1982), calmodulin-binding protein (Davis and Klee, 1981), or brain actin-binding protein (Shimo-Oka et al., 1983), has been extensively examined (Goodman and Zagon, 1984, 1986; Goodman et al., 1988). Brain spectrin comprises about $3 \%$ of mammalian neural membrane protein and is a 1,000,000 molecular weight fibrous protein with subunits of $240 \mathrm{kDa}(\alpha)$ and 235 $\mathrm{kDa}(\beta)$ forming an $(\alpha \beta)_{2}$ tetrameric complex. Brain spectrin contains binding sites for calmodulin (Davis and Klee, 1981; Kakiuchi et al., 1981; Glenney et al., 1982; Tsukita et al., 1983), ankyrin (Davis and Bennett, 1984a,b), brain protein 4.1 (amelin) (Goodman et al., 1984), synapsin I (Baines and Bennett, 1985), and F-actin (Bennett et al., 1982; Glenney et al., 1982). Interactions with these binding proteins are important for the attachment of spectrin to membrane surfaces and cytoskeletal structures.

The mammalian brain contains two isoforms of neurally localized spectrins, (240/235) and (240/235E) (Goodman et al., 1987), as well as an astrocyte-specific isoform, (240/235A) (Goodman et al., 1989). All three isoforms contain a $240 \mathrm{kDa}$ $\alpha$-subunit and a $235 \mathrm{kDa} \beta$-subunit in a $1: 1 \mathrm{~mol} / \mathrm{mol}$ ratio. At the light microscope level, brain spectrin $(240 / 235 \mathrm{E})$ is localized within neuronal cell bodies and their dendrites, as well as glia (Zagon et al., 1984; Riederer et al., 1986), while brain spectrin $(240 / 235)$ is found in neuronal cell bodies and axons (Riederer et al., 1986). At the ultrastructural level (Zagon et al., 1986), brain spectrin $(240 / 235 \mathrm{E})$ immunoreactivity is associated with the cytoplasmic surfaces of plasma membranes, organelles, and cytoskeletal components of neural cells. Brain spectrin (240/ $235 \mathrm{E}$ ) is also localized within dendritic spines and at postsynaptic densities. Brain spectrin $(240 / 235)$ immunoreactivity is associated with the plasma membranes of cell bodies and axons, cytoplasmic surfaces of mitochondria, and cytoskeletal componcnts. At prcsynaptic terminals, spcctrin (240/235) is localized to the plasma membrane and small synaptic vesicles.

The well-known architecture, synaptic circuitry, sensory processing, structure-function correlations, and accessibility and possibility of experimental manipulation have made the retina an ideal place to gain insight into the role of the cytoskeleton in neuronal function. Special attention has been directed toward the phoioreceptor cells with respect to cytoskeletal relationships, since these cells have the capacity to regenerate their photosensitive outer segment membranes (Young, 1967). Investigations of tubulin (Woodford and Blanks, 1989), actin (Vaughan and Fisher, 1987; Chaitin et al., 1988; Chaitin and Burnside, 1989; Vaughan and Lasater, 1990), intermediate filaments (Drager, 1983; Lemmon and Rieser, 1983; Shaw and Weber, 1984; To- 


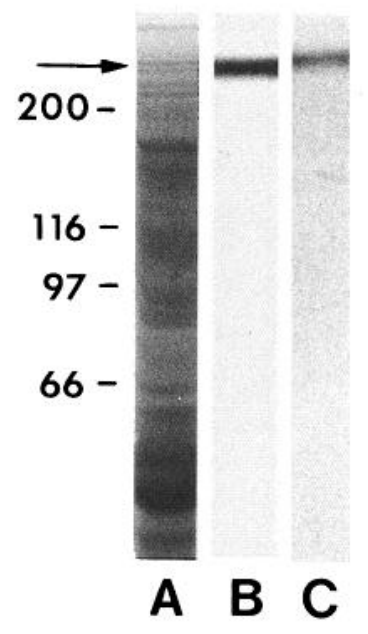

Figure 1. Retinal proteins separated on SDS-PAGE stained with Coomassie blue (lane A), immunostained with anti-brain spectrin (240/ 235E) IgG (lane B), and immunostained with anti-brain spectrin (240/ 235) IgG (lane $C$ ).

relli et al., 1989), and microtubule-associated proteins (Tucker and Matus, 1988; McKerracher et al., 1989; Okabe et al., 1989) in the intact, as well as cultured, retina have been documented. Some information about spectrin-like proteins in the avian (Lazarides et al., 1984) and amphibian (Drenckhahn and Bennett, 1987; Spencer et al., 1991) retinas has been reported. In mammals, Wong and Molday (1986) have shown that rod outer segments (ROSs) contain a protein related to erythrocyte spectrin. In a subsequent report, these workers found that this spectrin-like protein was directly associated with the $63 \mathrm{kDa}$ cGMPgated channel of bovine ROSs (Molday et al., 1990). Gundersen et al. (1991) have discovered that spectrin may play a role in maintaining the $\mathrm{Na}^{+}$and $\mathrm{K}^{+}$electrochemical gradients across the plasma membrane in retinal pigment epithelium.

In order to understand the function of spectrin in the retina, we must have an accurate and complete understanding of the localization of this molecule within the mammalian retina. In this report, we describe the results of a detailed examination in regard to the immunocytochemical localization of two brain spectrin isoforms, $(240 / 235)$ and $(240 / 235 \mathrm{E})$, within the retina and optic nerve.

\section{Materials and Methods}

Animals. Adult C57BL/6 mice were used in this study. Animals were housed in steel, solid-bottomed cages in an environment at $21 \pm 0.5^{\circ} \mathrm{C}$ with a relative humidity of $50 \pm 10 \%$ and a $12 \mathrm{hr}$ light $/ 12 \mathrm{hr}$ dark cycle with no twilight. Food and water were available ad libitum. All animals were allowed at least $5 \mathrm{~d}$ to acclimate to their surroundings prior to the beginning of the experiments.

Preparation and characterization of antibodies. Monospecific polyclonal antibodies to brain spectrin (240/235) and brain spectrin (240/ $235 \mathrm{E}$ ) were utilized in this study. These antibodies were prepared and characterized according to Riederer et al. (1986). In brief, native homogeneous mouse brain spectrin $(240 / 235)$ and erythrocyte spectrin were used as immunogens in rabbits. The antisera against erythrocyte and brain spectrin $(240 / 235)$ were passed through either a brain or erythrocyte spectrin-Sepharose 4B column, respectively, to yield antisera that would only detect the original antigen. The results of immunodot, immunoblot, and immunocytochemical analyses demonstrated that the erythrocyte spectrin antiserum detected only brain spectrin $(240 / 235 \mathrm{E})$ from total brain homogenate protein after affinity chromatography. The antiserum against the synaptic/axonal form of spectrin was specific for brain spectrin (240/235) after affinity chromatography.

Immunoblotting. Adult C57BL/6 mice were anesthetized with sodium pentobarbital $(30 \mathrm{mg} / \mathrm{kg}$, i.p. $)$ and perfused transcardially with phosphate-buffered saline (PBS); all perfusions were performed at $120 \mathrm{~mm}$ $\mathrm{Hg}$. Retinas were dissected for protein isolation and subsequent immunoblot analyses. Tissue was removed quickly and immersed in icecold $50 \mathrm{~mm}$ Tris- $\mathrm{HCl}, 150 \mathrm{~mm} \mathrm{NaCl}, \mathrm{pH} 7.4$ (TBS), containing leupeptin $(1 \mathrm{mg} / \mathrm{ml})$, bacitracin $(0.1 \mathrm{mg} / \mathrm{ml})$, thiorphan $(3 \mathrm{~mm})$, EGTA $(1 \mathrm{~mm})$, and phenylmethylsulfonyl fluoride $(0.6 \mathrm{mg} / \mathrm{ml})$. Samples were homogenized with a Polytron homogenizer and centrifuged at $2200 \times \mathrm{g}$, and the supernatant was collected and centrifuged at $2200 \times \mathrm{g}$. The supernatant obtained after the two initial spins was centrifuged at $39,000 \times$ $g$. The resulting pellet was separated by SDS-PAGE, utilizing a $7 \%$ polyacrylamide gel and a discontinuous buffer system (Laemmli, 1970); proteins were transferred from the SDS-polyacrylamide slab gels to nitrocellulose by the method of Towbin et al. (1979). Some preparations were stained with Coomassie blue. Primary antisera to brain spectrin $(240 / 235)$ and $(240 / 235 \mathrm{E})$ were used at a dilution of $1: 1000$; blots were incubated overnight at $4^{\circ} \mathrm{C}$ and visualized with ${ }^{125} \mathrm{I}$-protein $\mathrm{A}$.

Immunocytochemistry. Animals anesthetized with sodium pentobarbital were perfused intracardially with PBS. Animals were decapitated immediately, and their eyes were removed intact and frozen in isopentane cooled with liquid nitrogen; in some cases, cerebella were also removed and frozen. Sections of whole eye or cerebellum were cut on a Reichert Histostat cryostat at a thickness of $15 \mu \mathrm{m}$ and collected on gelatin-coated slides.

Sections were fixed in $95 \%$ ethanol at $4^{\circ} \mathrm{C}$ for $30 \mathrm{~min}$ and made permeable to antibodies by immersion in absolute acetone at $4^{\circ} \mathrm{C}$ for $30 \mathrm{~min}$. Tissues were washed in TBS for at least $30 \mathrm{~min}$ at room temperature and blocked with 3\% normal goat serum (NGS) in TBS for 30 min at $4^{\circ} \mathrm{C}$. Sections were incubated overnight at $4^{\circ} \mathrm{C}$ with antiserum to brain spectrin $(240 / 235 \mathrm{E})$ or antiserum to brain spectrin $(240 / 235)$ at a dilution of $1: 200$ in $1 \%$ NGS in TBS with $0.1 \%$ Triton X-100. Control retinas were incubated overnight in $3 \%$ NGS. Following a series of washes in TBS over $60 \mathrm{~min}$, sections were blocked with 3\% NGS in TBS for $30 \mathrm{~min}$. Tissues were incubated for $2 \mathrm{hr}$ at $4^{\circ} \mathrm{C}$ with rhodamineconjugated goat anti-rabbit IgG (Cappel Laboratories) at a dilution of $1: 100$ in $1 \%$ NGS in TBS with $0.1 \%$ Triton X-100. Sections were washed in TBS at room temperature for $60 \mathrm{~min}$ and mounted on coverslips with buffered glycerol (60\% glycerol, $40 \% 0.4 \mathrm{M} \mathrm{KHCO}_{3}$, pH 8.6).

\section{Results}

Expression of spectrin antigens in the retina and optic nerve Western blot analysis of immunoblots of retinal proteins indicated that immunoreactive brain spectrin (240/235) and brain spectrin $(240 / 235 \mathrm{E})$ were detected in the adult mouse retina (Fig. 1, lanes B and C). The two isoforms of brain spectrin migrated to the same regions as their respective isoforms in brain preparations. The antiserum to isoform $(240 / 235 \mathrm{E})$ appeared to recognize the $235 \mathrm{kDa}$ subunit preferentially, while the antiserum to isoform (240/235) recognized the $240 \mathrm{kDa}$

\footnotetext{
Figure 2. All figures are cross sections of the adult mouse retina. $A$, Low-magnification photomicrograph showing immunoreactivity detected in all layers of the retina. $G C$, Ganglion cell layer; $I N$, inner nuclear layer; $I P$, inner plexiform layer; $O N$, outer nuclear layer; $O P$, outer plexiform layer; $O L$, outer limiting membrane. $B$, Mouse retina stained only with the secondary antibody $(415 \times)$. $C$, Higher-magnification $(660 \times)$ micrograph showing brightly immunolabeled cells in the GC (arrow) and IN (arrowheads), and the weak immunoreactivity in the photoreceptor cell bodies of the ON; immunofluorescence was isolated to the cortical cytoplasm, with nuclei appearing nonreactive. $N F$, nerve fiber layer. $D$, An example of an immumolabeled ganglion cell (arrow) in the GC of the adult mouse $(435 \times)$; this ganglion cell is seen extending a process into the IP (arrowhead). $E$, Immunofluorescent cells in the IN were occasionally observed to extend processes into the IP and/or the OP $($ arrowheads $)(990 \times)$.
} 



(2)

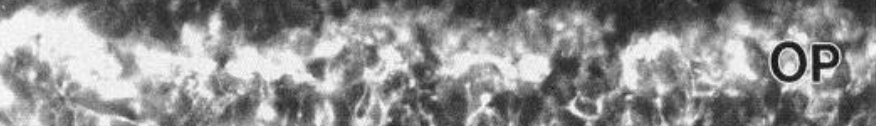

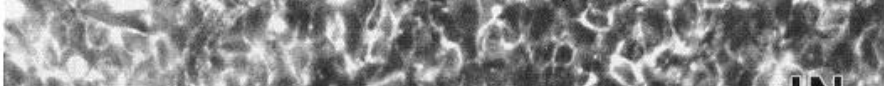

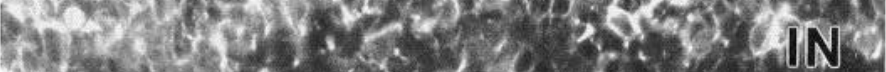

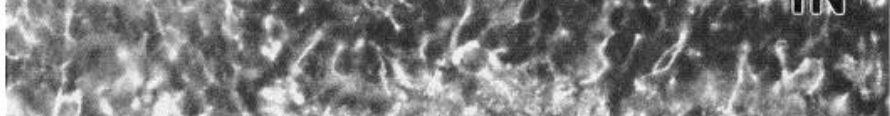

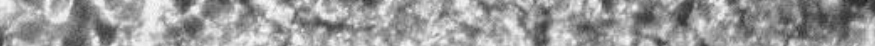

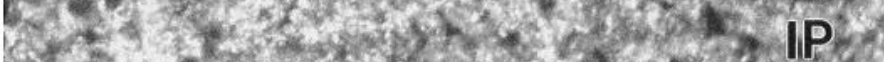

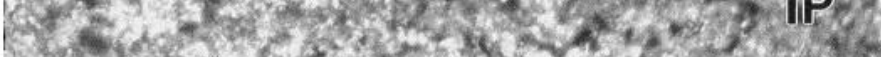
Why $x^{2}$.

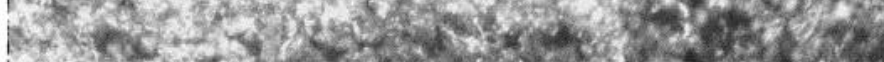

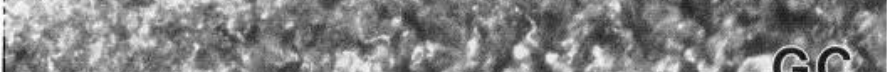

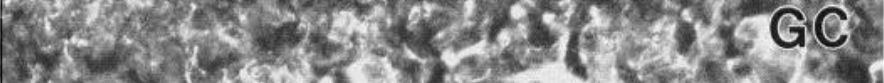

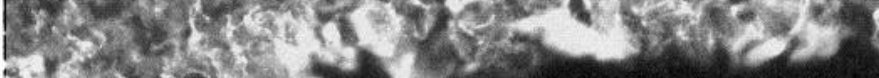

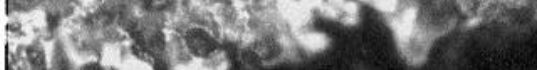

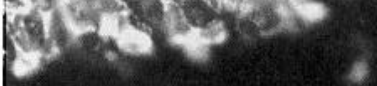

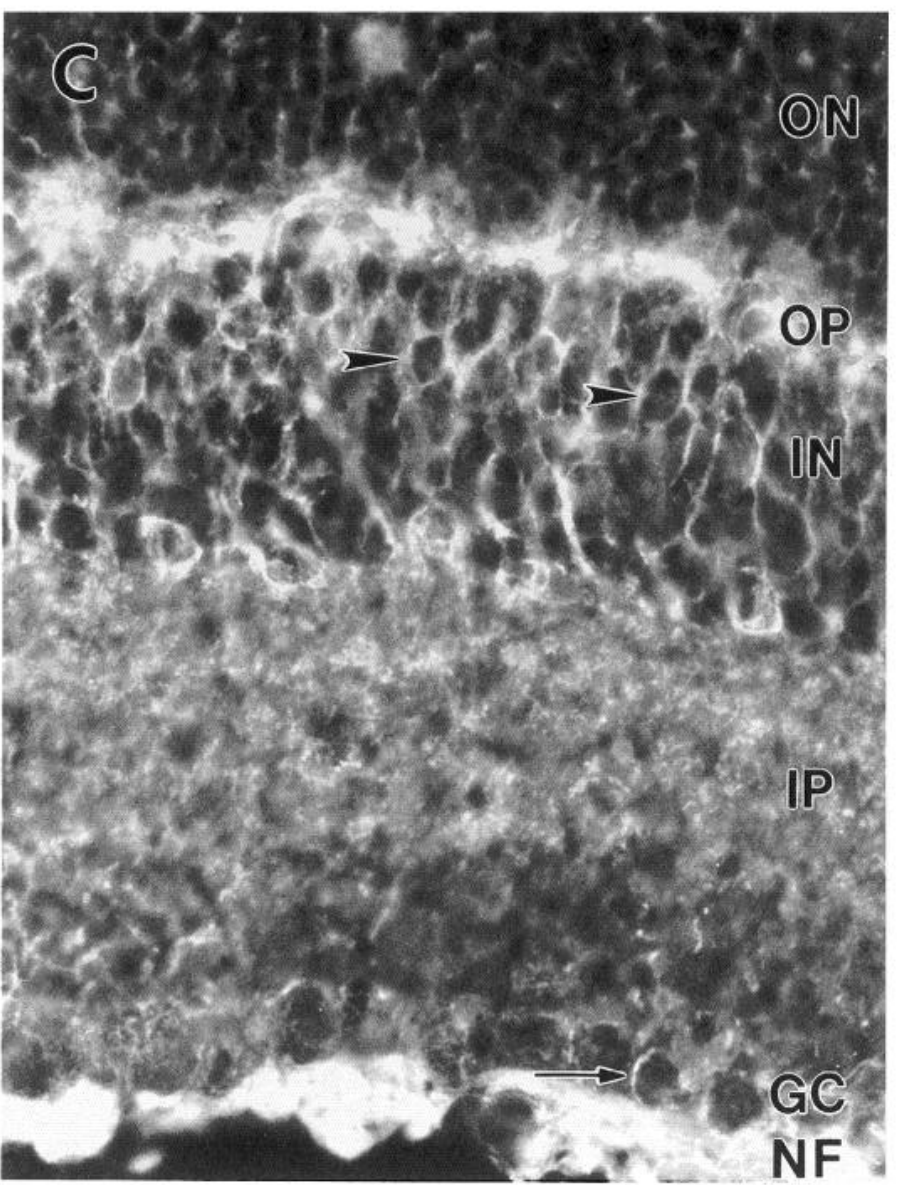

D

subunit, although both subunits were often detected to varying degrees with both antibodies.

\section{Immunocytochemical localization of spectrin antigens in retina and optic nerve}

Analysis of sections of mouse retina reacted with antiserum to brain spectrin $(240 / 235 \mathrm{E})$ revealed abundant immunoreactivity within the various layers of the retina (Fig. $2 A, C$ ). The most intense immunofluorescence was localized to the nerve fiber layer (NFL), ganglion cell layer (GCI ), inner nuclear layer (INL), and the outer plexiform layer (OPL). Other layers of the retina did not appear to stain as intensely as these, but the immunoreactivity detected by fluorescence was above that seen in control sections (Fig. 2B). Brain spectrin (240/235E) appeared to be localized to cell bodies of the GCL and INL (Fig. 2C); a low level of immunofluorescence was associated with the photoreceptor cell bodies of the outer nuclear layer (ONL) (Fig. 2C). The immunoreactivity found in cells populating the cellular layers of the retina was localized to the cytoplasm, with the nuclei of the cells appearing nonreactive (Fig. 2D,E). Ganglion cells in the GCL could be observed with immunoreactive processes extending into the inner plexiform layer (IPL) (Fig. 2D). Immunostained cells in the INL were identified tentatively as bipolar and amacrine cells (Fig. 2C) based on the size and location of their somata; labeled horizontal cells could not be identified with certainty. While immunolabeled processes arose from cells in the INL (Fig. $2 E$ ), they could not be traced into their finest processes. Based on the intensity of immunofluorescence, two layers of immunoreactivity could be distinguished in the IPL (Fig. $2 A, C$ ). The IPL adjacent to the INL exhibited considerable immunofluorescence, whereas the IPL proximal to the GCL was not as immunoreactive. This pattern of immunoreactivity may correspond to the stratification of rod bipolar cell axons within the IPL. The OPL showed intense immunolabeling (Fig. $2 E$ ) that often appeared to be arranged in globular units; this pattern of immunofluorescence present in the OPL (Fig. 2A-C) suggests that receptor terminals, perhaps rod spherules, were stained. Brain spectrin $(240 / 235 \mathrm{E})$ could be localized to the NFL and to individual fibers within the optic nerve (Fig. $3 A, B)$.

In view of the unexpected immunoreactivity of the optic nerve with anti-brain spectrin $(240 / 235 \mathrm{E}) \mathrm{IgG}$, sections of adult mouse cerebellum prepared similarly were processed with the brain spectrin $(240 / 235 \mathrm{E})$ antiserum. The results were consistent with previous findings (Zagon et al., 1984; Riederer et al., 1986). Brain spectrin $(240 / 235 \mathrm{E})$ was found in the cortical cytoplasm of neural cells such as internal granule and Purkinje neurons, the molecular layer was lightly stained, and the medullary layer was not immunoreactive (Fig. 3C).

Sections of the retina stained with antiserum to brain spectrin (240/235) (Fig. 4A) exhibited an overall diffuse immunoreactivity. Brain spectrin $(240 / 235)$ antigen was present in most cell bodies; cell nuclei were unstained. Cells in the ONL, INL, and GCL were all labeled with the same intensity. An area that appeared to possess abundant spectrin $(240 / 235)$ immunoreactivity was the outer limiting membrane, the border between the ONL and the photoreceptor outer segments (Fig. 4A). Analysis of sections containing the optic nerve indicated that brain spectrin $(240 / 235)$ immunoreactivity was present within the NFL and the optic nerve (Fig. $4 C, D$ ). Observations indicated that the immunofluorescence was diffusely distributed; fibers were not detected by immunostaining in the optic nerve or the NFL.
Distinct patterns of lamination were not found in the IPL for brain spectrin $(240 / 235)$ as detected for brain spectrin $(240 /$ $235 \mathrm{E}$ ), but often the OPL did exhibit a concentration of immunofluorescence in globular units similar to that found in the OPL of retinas stained for brain spectrin $(240 / 235 \mathrm{E})$ (Fig. $4 A, B)$.

\section{Discussion}

In the present study, Western blotting and immunocy tochemical techniques were utilized in conjunction with antisera directed against two mammalian brain spectrin isoforms to the retina and optic nerve of the adult mouse. We report that a cytoskeletal system composed of brain spectrin $(240 / 235)$ and brain spectrin $(240 / 235 \mathrm{E})$ is present in the mouse retina and optic nerve. Western blotting experiments revealed the presence of proteins in retinal extracts that migrated in correspondence to the molecular weights of isoforms previously isolated from the mouse brain (Riederer et al., 1986). These proteins could be stained specifically using antisera to both spectrin isoforms. The cellular immunoreactivity for both isoforms was located in the cytoplasm, with cell nuclei unstained. Our findings using immunocytochemistry also showed discrete localization for each of the spectrin antigens. Brain spectrin (240/235E) was present in cell bodies located in the INL and GCL. Sections labeled with antibrain spcctrin (240/235) IgG also showed abundant immunofluorescence, but the immunoreactivity was not as precisely localized as seen for the $(240 / 235 \mathrm{E})$ isoform. Whereas individual cell somata were easily identified in tissue stained for brain spectrin $(240 / 235 \mathrm{E})$, cell boundaries in retina labeled with antibrain spectrin (240/235) IgG were not apparent.

Zagon et al. (1986) and Riederer et al. (1986) have shown that there are two distinct isoforms of spectrin in the mammalian brain. Brain spectrin $(240 / 235 \mathrm{E})$ is associated with dendrites and neuronal somata predominantly, while brain spectrin $(240 / 235)$ is associated with neuronal cell soma and axons. The present observations reveal that spectrin in the mammalian retina and optic nerve has a somewhat different pattern of distribution from the brain. Brain spectrin (240/235E) immunoreactivity is present in processes arising from retinal cells, but it is difficult at the light microscope level of resolution to distinguish axons and dendrites clearly. In this study, however, we found that brain spectrin $(240 / 235 \mathrm{E})$, a predominantly dendritic form of spectrin in the CNS, is in great abundance in the NFL as well as the optic nerve. Both of these structures are composed of glia and the axon fibers of retinal ganglion cells. The association of brain spectrin $(240 / 235 \mathrm{E})$ with axonal elements in the retina is a novel observation. Indeed, to verify that our immunocytochemical procedures for the retina were similar to those used in earlier studies, we also stained adult mouse cerebellum with antibodies to brain spectrin (240/235E). Our results were consistent with earlier findings showing that axons in the brain do not contain spectrin (240/235E) antigens (Zagon and Goodman, 1989). The reason(s) for this difference between the retina and the brain with respect to brain spectrin (240/ $235 \mathrm{E}$ ) is presently unclear. Perhaps antibodies to brain spectrin $(240 / 235 \mathrm{E})$ are recognizing a spectrin isoform unique to the retina. Alternatively, the antibodies to spectrin $(240 / 235 \mathrm{E})$ may be associated with the glia of these axonal areas; immunoelectron microscopic studies are needed to clarify this matter. With regard to brain spectrin (240/235), neural cell bodies and axonrich areas did appear to contain this isoform, but the diffuse nature of the immunolabeling in the retina made it difficult to discern all of the cellular elements related to this antigen. Once 

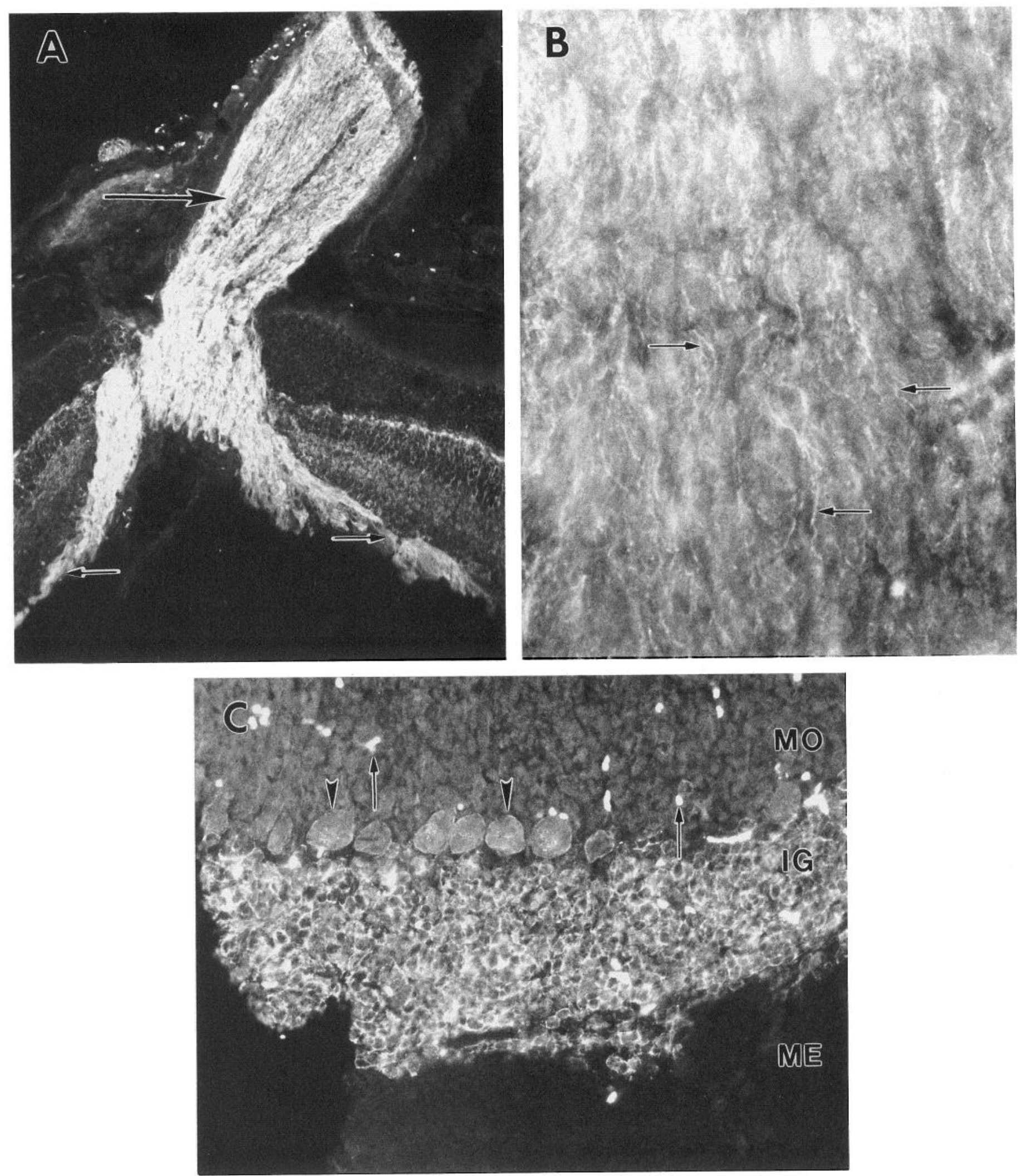

Figure 3. All figures are cross sections of adult mouse retina immunostained with anti-brain spectrin (240/235E) IgG. $A$, The intense immunofluorescence seen in the retina $(170 \times)$ is also present in the NF (small arrows) and the optic nerve (large arrow). B, A high-magnification ( $875 \times$ ) micrograph of sagittally sectioned optic nerve; note the immunolabeled fibers (arrows) within the body of the optic nerve. $C$, A light micrograph $(380 \times)$ of adult mouse cerebellum stained with anti-brain spectrin $(240 / 235 \mathrm{E})$ serum; granule and Purkinje cells of the internal granule layer (IG) were brightly immunofluorescent, the molecular layer $(M O)$ was lightly stained, and the medullary layer $(M E)$ was nonreactive. Arrowheads, Purkinje cells; arrows, red blood cells. 


\section{A}

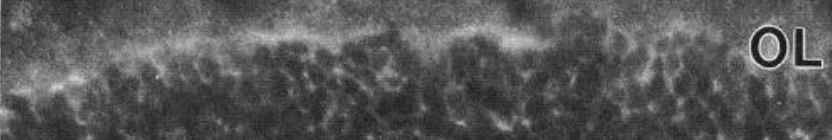

ON
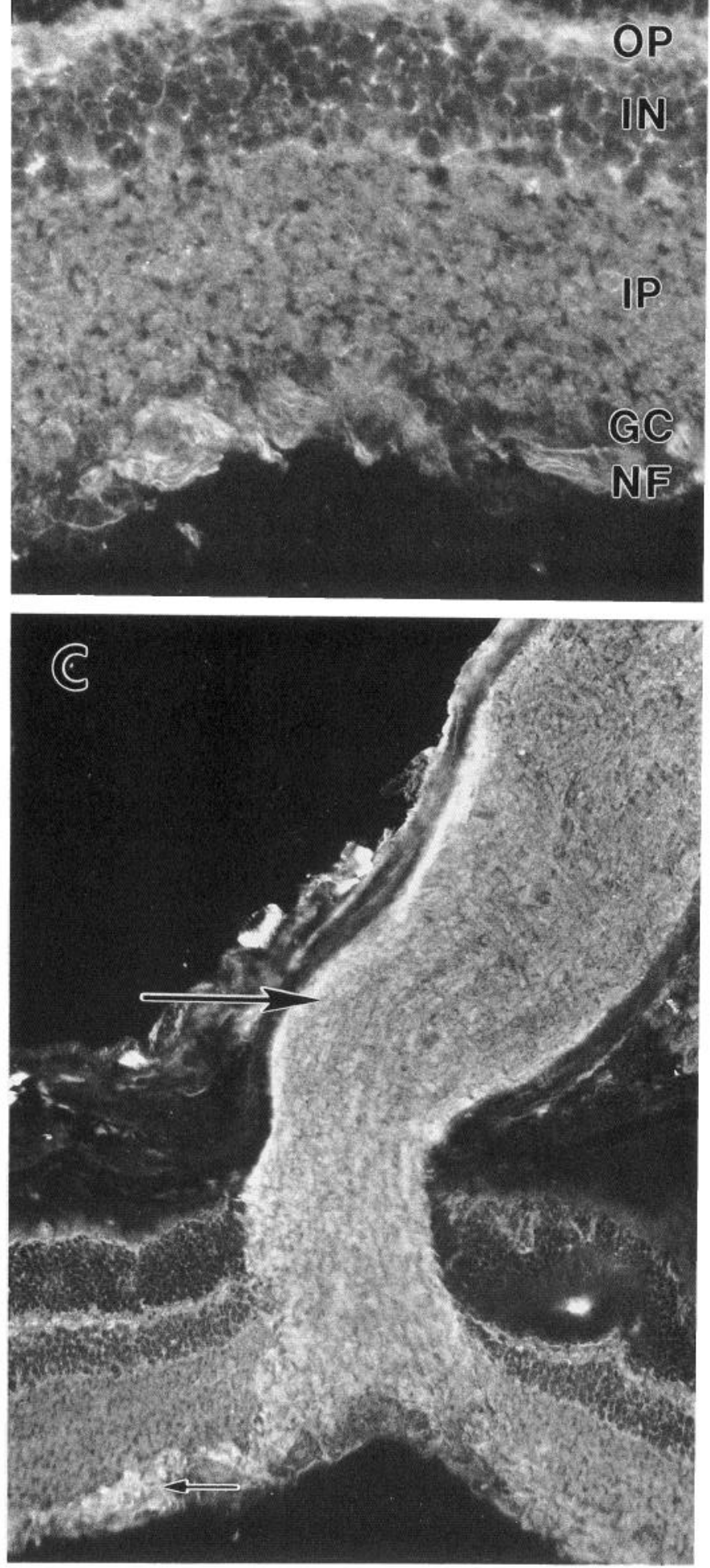
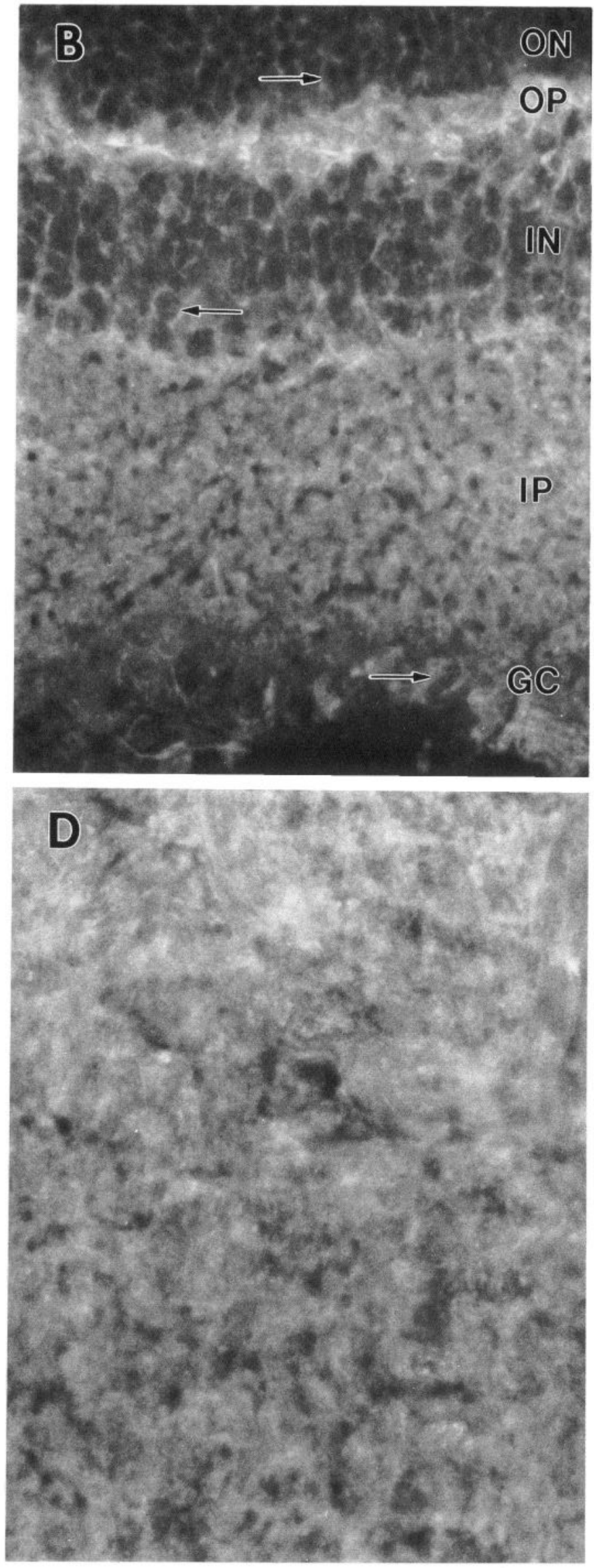
again, immunoelectron microscopy will be needed to resolve the distribution of the spectrin antigen in the retina.

A number of investigators have reported the detection and localization of spectrin antigens in the vertebrate retina. The avian optic system contains a major membrane-associated axonally transported form of spectrin (Lazarides et al., 1984). Spectrin detected by Lazarides et al. (1984) using antibodies to the $\alpha$-subunit was present in axon fibers of the optic nerve, the cell bodies of ganglion cells, processes in the IPL and OPL, and cell bodies of the INL and rods and cones in the ONL; outer segments of rods and cones did not contain this form of spectrin. An erythrocyte-related form of spectrin was also detected in the avian retina. This form of spectrin was more anatomically restricted. Antibodies to the $\beta$-subunit of the erythrocyte-related form of spectrin labeled the plasma membrane of dendrites and cell bodies of ganglion cells but did not stain optic nerve fibers. Drenckhahn and Bennett (1987) have examined the location of spectrin in the avian retina with an antibody to bovine brain spectrin and report immunocytochemical staining of the membrane of axonal processes and synaptic endings, and cone and rod outer segments. Spencer et al. (1991) have detected nonerythroid $\alpha$-spectrin in cones of amphibians and suggest that this protein may participate in maintaining the morphology of cone inner segments. The present study is consistent with the findings of spectrin antigens in the retina. Comparisons between investigations of mammalian, avian, and amphibian retinas, however, are difficult because of differences in species examined, immunocytochemical preparations utilized, and, in some cases, lack of characterization or specific information about the nature of the antibodies to spectrin (Drenckhahn and Bennett, 1987; Spencer et al., 1991). Moreover, unlike mammals, avian spectrin has an antigenically and structurally constant $\alpha$-subunit (Glenney and Glenney, 1983a,b, 1984). Therefore, antibodies against the $\alpha$-subunit, such as used by Lazarides et al. (1984) to detect the brain-specific form of spectrin, would detect all chicken brain spectrin subtypes.

In the mammalian retina, Wong and Molday (1986) have found that the ROS of bovine photoreceptor cells contain an $M_{r} 240,000$ polypeptide related to the $\alpha$-subunit of rbc spectrin. This protein may constitute a major component of a filamentous network lining the inner surface of the ROS plasma membrane and may be related to the stability of the ROS and the plasma membrane. In a subsequent study, Molday et al. (1990) demonstrated that this $240 \mathrm{kDa}$ protein, which exhibited immunochemical cross-reactivity with rbc spectrin, was associated directly with the $63 \mathrm{kDa}$ cGMP-gated channel of bovine ROS; this finding raises the question of whether cytoskeletal elements interact with channel proteins and ion pumps. In a related study, Gundersen et al. (1991) reported that, in contrast to most transporting epithelia (e.g., urinary or digestive systems), retinal pigment epithelium displays a different polarity with regard to $\mathrm{Na}^{+}, \mathrm{K}^{+}$-ATPase and that this is linked to a reversal of the ankyrin-spectrin submembrane cytoskeleton. The results of the present study extend these observations by demonstrating that spectrin is of widespread occurrence within the mammalian retina and optic nerve. The function of spectrin in the retina requires elucidation. The spectrin-based membrane skeleton in erythrocytes is involved in the regulation of cell morphology and immobilization of integral membrane proteins. Retinal spectrin may be postulated to participate in membrane anchorage of cortical actin, control of neural cell shape, maintenance of membrane structural integrity, compartmentalization and polarization of neuronal cells, regulation of the lateral mobility of integral membrane receptors, and/or synaptic transmission. Another area of importance for spectrin may be related to the unique regeneration of the photoreceptor outer segments in the retina (Young, 1967; Young and Bok, 1969). The continuing regeneration and remodeling of the photoreceptors involves the regular synthesis of disk membrane and proteins, and their transport and assembly into functional rod and cone outer segments. Whether the spectrin-based membrane cytoskeleton plays a role in the machinery required for the cells to regenerate their outer segments on a daily basis warrants attention.

\section{References}

Baines AJ, Bennet V (1985) Synapsin I is a spectrin-binding protein immunologically related to erythrocyte protein 4.1 . Nature $315: 410$ 413.

Bennett V (1990) Spectrin-based membrane skeleton: a multipotential adaptor between plasma membrane and cytoplasm. Physiol Rev 70: 1029-1065.

Bennett V, Davis J, Fowler W (1982) Brain spectrin, a membraneassociated protein related in structure and function to erythrocyte spectrin. Nature 299:126-131.

Burridge K, Kelly T, Mangeat P (1982) Nonerythrocyte spectrins: actin-membrane attachment proteins occurring in many cell types. $J$ Cell Biol 95:478-486.

Chaitin MH, Burnside B (1989) Actin filament polarity at the site of rod outer segment disk morphogenesis. Invest Ophthalmol Vis Sci 30:2461-2469.

Chaitin MH, Carlsen RB, Samara GJ (1988) Immunogold localization of actin in developing photoreceptor cilia of normal and rds mutant mice. Exp Eye Res 47:437-446.

Davis J, Bennett V (1984a) Brain ankyrin-a membrane associated protein with binding sites for spectrin, tubulin and the cytoplasmic domain of the erythrocyte anion channel. J Biol Chem 259:1355013559.

Davis JQ, Bennett V (1984b) Brain ankyrin-purification of a 72,000 $M_{r}$ spectrin-binding domain. J Biol Chem 259:1874-1881.

Davis PJA, Klee CB (1981) Calmodulin binding proteins: a high molecular weight calmodulin-binding protein from bovine brain. Biochem Int 3:203-212.

Drager UC (1983) Coexistence of neurofilaments and vimentin in a neurone of adult mouse retina. Nature 303:169-172.

Drenckhahn D, Bennett V (1987) Polarized distribution of $M, 210,000$ and 190,000 analogs of erythrocyte ankyrin along the plasma membrane of transporting epithelia, neurons and photoreceptors. Eur $\mathbf{J}$ Cell Biol 43:479-486.

Glenney JR, Glenney P (1983a) Fodrin is the general spectrin-like protein found in most cells whereas spectrin and the TW protein have restricted distribution. Cell 34:503-512.

Glenney JR, Glenney P (1983b) Spectrin, fodrin and TW260/240: a family of related proteins lining the plasma membrane. Cell Motil 3: 671-682.

Glenney JR, Glenney P (1984) Comparison of spectrin isolated from erythrocyte and non-erythroid sources. Eur J Biochem 144:529-539. Glenney JR, Glenney P, Weber K (1982) Erythroid spectrin, brain

\footnotetext{
Figure 4. A, Low-magnification $(410 \times)$ light micrograph showing the mouse retina in cross section stained with antiserum to brain spectrin (240/ 235). $B$, Immunoreactive cells (arrows) in the cellular layers of the retina; note that the diffuse immunoreactivity is localized to the cytoplasm, with the nuclei not stained $(660 \times)$. C, A section immunolabeled for brain spectrin (240/235) indicating the presence of this isoform in the optic nerve (large arrow) as well as in the retina $(170 \times)$. Small arrow, nerve fiber layer. $D$, A higher-magnification $(875 \times)$ micrograph of the sagittally sectioned optic nerve. Immunoreactivity was present, but no immunofluorescent fibers were observed. See Figure 2 for abbreviations.
} 
fodrin, and intestinal brush border proteins (TW-260/240) are related molecules containing a common calmodulin-binding subunit bound to a variant cell type specific subunit. Proc Natl Acad Sci USA 79: 4002-4005.

Goodman SR, Zagon IS (1984) Brain spectrin: a review. Brain Res Bull 13:813-832.

Goodman SR, Zagon IS (1986) The neural cell spectrin skeleton: a review. Am J Physiol 250:C347-C360.

Goodman SR, Zagon IS, Kulikowski RR (1981) Identification of a spectrin-like protein in nonerythroid cells. Proc Natl Acad Sci USA 78:7570-7574.

Goodman SR, Casoria LA, Coleman DB, Zagon IS (1984) Identification and location of brain protein 4.1. Science 224:1433-1436.

Goodman SR, Zagon IS, Riederer BM (1987) Spectrin isoforms in the mammalian brain. Brain Res Bull 18:787-792.

Goodman SR, Krebs KE, Whitfield CF, Riederer BM, Zagon IS (1988) Spectrin and related molecules. CRC Crit Rev Biochem 23:171-234.

Goodman SR, Lopresti LL, Riederer BM, Sikorski A, Zagon IS (1989) Brain spectrin (240/235A): a novel astrocyte specific spectrin isoform. Brain Res Bull 23:311-316.

Gundersen D, Orlowski J, Rodriguez-Boulan E (1991) Apical polarity of $\mathrm{Na}, \mathrm{K}-\mathrm{ATPase}$ in retinal pigment epithelium is linked to a reversal of the ankyrin-fodrin submemhrane skeleton. J Cell Biol 112:863872.

Kakiuchi S, Sobue K, Fujita M (1981) Purification of a $240,000 M_{r}$ calmodulin-binding protein from a microsomal fraction of brain. FEBS Lett 132:144-148.

Kakiuchi S, Sobue K, Morimoto K, Kanda K (1982) A spectrin-like calmodulin-binding protein (calspectin) of brain. Biochem Int 5:755762.

Laemmli UK (1970) Cleavage of structural proteins during assembly of the head of bacteriophage $T_{4}$. Nature 227:680-685.

Lazarides E, Nelson WJ, Kasamatsu T (1984) Segregation of two spectrin forms in the chicken optic system: a mechanism for establishing restricted membrane-cytoskeletal domains in neurons. Cell 36:269-278

Lemmon V, Rieser G (1983) The developmental distribution of vimentin in the chick retina. Dev Brain Res 11:191-197.

Levine J, Willard M (1981) Fodrin: axonally transported polypeptides associated with the internal periphery of many cells. J Cell Biol 90: 631-643.

McKerracher L, Vallee RB, Aguayo AJ (1989) Microtubule-associated protein 1A (MAP 1A) is a ganglion cell marker in adult rat retina. Vis Neurosci 2:349-356.

Molday LL, Cook NJ, Kaupp UB, Molday RS (1990) The cGMPgated cation channel of bovine rod photoreceptor cells is associated with a $240-\mathrm{kDa}$ protein exhibiting immunochemical cross-reactivity with spectrin. J Biol Chem 265:18690-18695.

Okabe S, Shiomura Y, Hirokawa N (1989) Immunocytochemical localization of microtubule-associated proteins $1 \mathrm{~A}$ and 2 in the rat retina. Brain Res 483:335-346.
Repasky E, Granger B, Lazarides E (1982) Widespread occurrence of avian spectrin in nonerythroid cells. Cell 29:821-833.

Riederer BM, Zagon IS, Goodman SR (1986) Brain spectrin (240/ $235)$ and brain spectrin (240/235E): two distinct spectrin subtypes with different locations within mammalian neural cells. J Cell Biol 102:2088-2097.

Shaw G, Weber K (1984) The intermediate filament complement of the retina: a comparison between different mammalian species. Eur J Cell Biol 33:95-104.

Shimo-Oka T, Ohnishi K, Watanabe Y (1983) Further characterization of a brain high molecular weight actin-binding protein (BABP): interaction with brain actin and ultrastructural studies. J Biochem (Tokyo) 93:977-987.

Spencer M, Moon RT, Milam AH (1991) Membrane skeleton protein 4.1 in inner segments of retinal cones. Invest Ophthalmol Vis Sci 32: $1-7$.

Torelli S, Sogos V, Marzilli MA, D'Atri M, Gremo F (1989) Developmental expression of intermediate flament proteins in the chick embryo retina: in vivo and in vitro comparison. Exp Biol 48:187-196.

Towbin H, Staehelin T, Gordon J (1979) Electrophoretic transfer of proteins from polyacrylamide gels to nitrocellulose sheets: procedure and some applications. Proc Natl Acad Sci USA 76:4350-4354.

Tsukita S, Tsukita S, Ishikawa H, Kurokawa M, Morimoto K, Sobue $\mathrm{K}$, Kakiuchi S (1983) Binding sites of calmodulin and actin on the brain spectrin, calspectin. J Cell Biol 97:574-578.

Tucker RP, Matus AI (1988) Microtubule-associated proteins characteristic of embryonic brain are found in the adult mammalian retina. Dev Biol 130:423-434.

Vaughan DK, Fisher SK (1987) The distribution of F-actin in cells isolated from vertebrate retinas. Exp Eye Res 44:393-406.

Vaughan DK, Lasater EM (1990) Distribution of F-actin in bipolar and horizontal cells of bass retinas. Am J Physiol 259:C205-C214.

Wong S, Molday RS (1986) A spectrin-like protein in retinal rod outer segments. Biochemistry 25:6294-6300.

Woodford BJ, Blanks JC (1989) Localization of actin and tubulin in developing and adult mammalian photoreceptors. Cell Tissue Res 256:495-505.

Young RW (1967) The renewal of photoreceptor outer segments. J Cell Biol 33:61-72.

Young RW, Bok D (1969) Participation of the retinal pigment epithelium in the rod outer segment renewal process. J Cell Biol 42:392403.

Zagon IS, Goodman SR (1989) Absence of brain spectrin (240/235) in dendrites of mammalian brain. Brain Res Bull 23:19-24.

Zagon IS, McLaughlin PJ, Goodman SR (1984) Localization of spectrin in mammalian brain. J Neurosci 4:3089-3100.

Zagon IS, Higbee R, Riederer BM, Goodman SR (1986) Spectrin subtypes in the mammalian brain: an immunoelectron microscopic study. J Neurosci 6:2977-2986. 